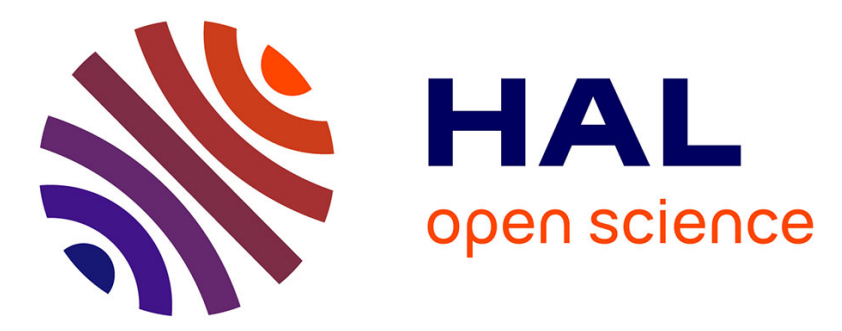

\title{
Zirconia matrix composite dispersed with stainless steel particles: Processing and oxidation behavior
}

\author{
Jinane Tarabay, Véronique Peres, Eric Serris, François Valdivieso, Michèle
}

Pijolat

\section{- To cite this version:}

Jinane Tarabay, Véronique Peres, Eric Serris, François Valdivieso, Michèle Pijolat. Zirconia matrix composite dispersed with stainless steel particles: Processing and oxidation behavior. Journal of the European Ceramic Society, 2013, 33 (6), pp.1101-1110. 10.1016/j.jeurceramsoc.2012.11.020 . hal00783283

\section{HAL Id: hal-00783283 \\ https://hal.science/hal-00783283}

Submitted on 12 Feb 2013

HAL is a multi-disciplinary open access archive for the deposit and dissemination of scientific research documents, whether they are published or not. The documents may come from teaching and research institutions in France or abroad, or from public or private research centers.
L'archive ouverte pluridisciplinaire HAL, est destinée au dépôt et à la diffusion de documents scientifiques de niveau recherche, publiés ou non, émanant des établissements d'enseignement et de recherche français ou étrangers, des laboratoires publics ou privés. 


\title{
Zirconia matrix composite dispersed with stainless steel particles: processing and oxidation behavior
}

Jinane Tarabay $^{(\mathrm{a})}$, Véronique Peres ${ }^{(\mathrm{a})}$, Eric Serris ${ }^{(\mathrm{a})}$, François Valdivieso ${ }^{(\mathrm{b})}$, Michèle Pijolat ${ }^{(\mathrm{a})}$

(a) Ecole Nationale Supérieure des Mines, SPIN-ENSM.SE, PRESSIC-ENSM.SE, LGF UMR 5307, F-42023 Saint Etienne. France

(b) Ecole Nationale Supérieure des Mines, SMS-ENSM.SE, LGF UMR 5307, F-42023 Saint Etienne. France

Corresponding authors: peres@emse.fr

Tel: $+33477420070 \quad$ Fax: +33477499694

\begin{abstract}
Materials with non uniform properties are being developed to optimize several functions of industrial components in severe atmospheres at high temperature. These composites called $\mathrm{M}(\mathrm{p})-\mathrm{CMC}(\mathrm{s})$ : "ceramic matrix composites dispersed with metal particles" are candidates for high-temperature structure materials as functionally graded materials (FGMs) such as intermediate components between electrolyte and interconnecting components in SOFC.

Preparation of a model composite $\mathrm{M}(\mathrm{p})-\mathrm{CMC}(\mathrm{s})$ is described. Powder metallurgy process is used to obtain a dense composite ( $98 \%$ of the theoretical density) based on yttrium stabilized zirconia for the ceramic part and on 304L stainless steel for the metallic part. The characteristics of this material as well as it behavior under oxidation at high temperature are reported.
\end{abstract}

Keywords: $\mathrm{ZrO}_{2}$, powder metallurgy process, composite, corrosion, solid fuel.

\section{Introduction}

New challenges of modern high technology require the development of technical materials with combined properties or functions [1,2].

Ceramic matrix composites dispersed with metallic particles, called $\mathrm{M}(\mathrm{p})-\mathrm{CMC}(\mathrm{s})$ [3], are one of the promising materials for high performance applications under severe environment such as high temperature. This new material design offers the possibility to combine heat resistance, corrosion resistance and wear resistance due to the ceramic phase, with mechanical strength and electric conductivity provided by the metal phase [4]. 
M(p)-CMC(s) are nowadays the candidates for functionally graded materials (FGMs) developed for their multiple functions and reduced cost $[5,6]$. Recent studies highlight the use of graded $\mathrm{M}(\mathrm{p})$ $\mathrm{CMC}(\mathrm{s})$ materials as intermediate components between interconnectors and electrolyte in the oxide fuel cell SOFC [4, 7].

The model $\mathrm{M}(\mathrm{p})-\mathrm{CMC}(\mathrm{s})$ described in this study is based on yttrium stabilized $\mathrm{ZrO}_{2}$ and $304 \mathrm{~L}$ stainless steel materials.

Zirconia is an interesting ionic ceramic material with high oxygen diffusion at temperature around 800 ${ }^{\circ} \mathrm{C}$. No interaction between $\mathrm{ZrO}_{2}$ and stainless steel has been reported [8, 9]. The thermal expansion coefficients of zirconia $\left(11.10^{-6}{ }^{\circ} \mathrm{K}^{-1}\right)$ and of the metal phase $\left(18.10^{-6}{ }^{\circ} \mathrm{K}^{-1}\right)$ for temperature close to $1000{ }^{\circ} \mathrm{C}$ are close together which should lower thermal stresses during the sintering of the composite.

The present work is dedicated to the $304 \mathrm{~L}(\mathrm{p})-\mathrm{ZrO}_{2}(\mathrm{~s})$ composite manufacturing based on powder metallurgy process : blending of powders, granulation, pressing and sintering at $1350{ }^{\circ} \mathrm{C}$ under dry hydrogen and argon atmosphere. This process allows controlling the composition and the microstructure of the material $[10,11]$. The characterizations of the sintered samples are reported. Finally, the oxidation behavior of the model $304 \mathrm{~L}(\mathrm{p})-\mathrm{ZrO}_{2}(\mathrm{~s})$ composite, studied by means of thermogravimetry (TGA) under $20 \% \mathrm{O}_{2}$ in helium at $700{ }^{\circ} \mathrm{C}$ and $800{ }^{\circ} \mathrm{C}$, is presented. Based on Nanko's study [3], the oxidation will normally only be due to stainless steel particles inside the zirconia matrix.

\section{Experimental procedure}

\subsection{Basic materials}

The starting ceramic powder is yttrium oxide doped $\mathrm{ZrO}_{2}$ with a specific surface area of $14.6 \mathrm{~m}^{2} / \mathrm{g}$. This value corresponds to a crystallite size, considering a spherical particle, around $67 \mathrm{~nm}$. The atomized TZ-3Y-E zirconia powder doped with $3 \mathrm{~mol} \%$ of yttrium oxide was supplied by the Japanese company Tosoh. Its composition is given in Table I.

Table I. Chemichal composition of $\mathrm{ZrO}_{2}$ powder.

\begin{tabular}{ccccc}
\hline Chemical composition (mass \%) & $\mathrm{ZrO}_{2}$ & $\mathrm{Y}_{2} \mathrm{O}_{3}$ & $\mathrm{Al}_{2} \mathrm{O}_{3}$ & $\mathrm{SiO}_{2}$ \\
\hline Zirconia TZ-3Y-E & base & 5.2 & 0.25 & $<0.002$ \\
\hline
\end{tabular}


Laser granulometry analysis (Malvern instruments, Mastersizer 2000) of TZ-3Y-E zirconia powder shows a multimodal size distribution in the range 0.1 to $100 \mu \mathrm{m}$ (figure 1 ). The mode close to $100 \mu \mathrm{m}$ corresponds to the primary atomized particles. The other modes correspond to broken particles due to the sample preparation (powder dilution in water).

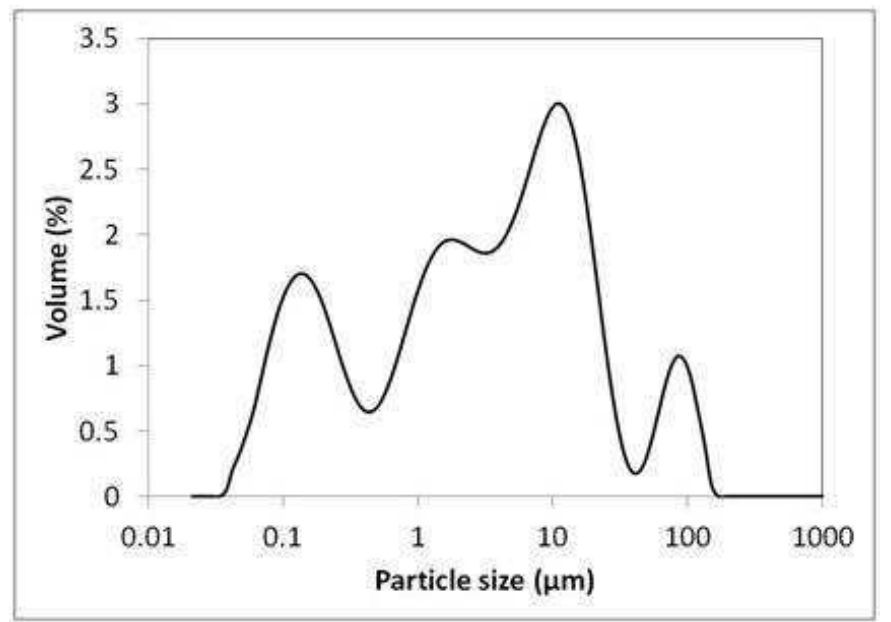

Fig.1. Laser granulometry of $\mathrm{TZ}-3 \mathrm{Y}-\mathrm{E} \mathrm{ZrO}_{2}$ powder

The starting metal powder is austenitic 304L stainless steel atomized in water as supplied by Hoganas Belgium. The powder density measured with picnometry method is closed to $99.65 \%$ of the theoretical density. Its specific surface area measured due to BET Krypton adsorption method is $0.06 \mathrm{~m}^{2} / \mathrm{g}$. This value corresponds to a crystallite size, considering a spherical particle, around $13 \mu \mathrm{m}$ which is $\sim 200$ times bigger than the zirconia crystallites.

The chemical composition of the 304L stainless steel powder is given in Table II.

Table II. Chemical composition of 304L stainless steel powder.

\begin{tabular}{llllllllll}
\hline $\begin{array}{l}\text { Chemical } \\
\text { composition }\end{array}$ & $\mathbf{F e}$ & $\mathbf{C r}$ & $\mathbf{N i}$ & $\mathbf{S i}$ & $\mathbf{C}$ & $\mathbf{S}$ & $\mathbf{M n}$ & $\mathbf{P}$ & $\mathbf{O}$ \\
\hline mass $(\%)$ & base & 19.1 & 11 & 0.8 & 0.013 & 0.004 & 0.1 & 0.011 & 0.27 \\
\hline
\end{tabular}

Laser granulometry (figure 2) shows the particle size distribution with one main mode of particle diameter in the range 10 to $200 \mu \mathrm{m}$ with a maximum at $\sim 80 \mu \mathrm{m}$. 


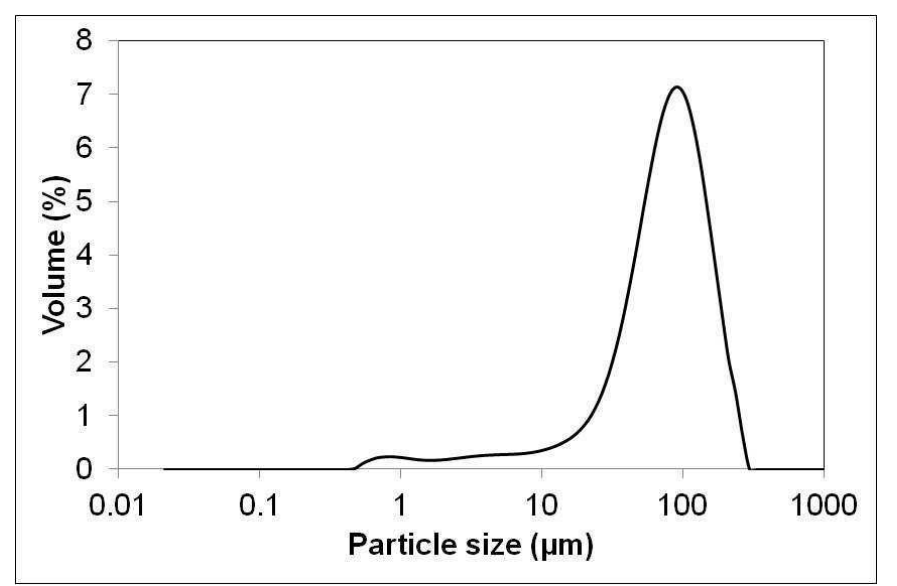

Fig.2. Laser granulometry of 304L stainless steel powder

Figure 3-a, shows individual particles of 304L stainless steel powder. In figure 3-b, at a higher magnification, a native oxide layer can be observed around the particles. XRD analysis (D 5000 Siemens) of the metallic powder does not show any oxide diffraction peaks (figure 4). However, it can be supposed that the amount of oxide is too low to be detected $(<1 \mathrm{vol} \%)$. The oxide layer is probably $\mathrm{Cr}_{2} \mathrm{O}_{3}$ as expected for this kind of alloy.

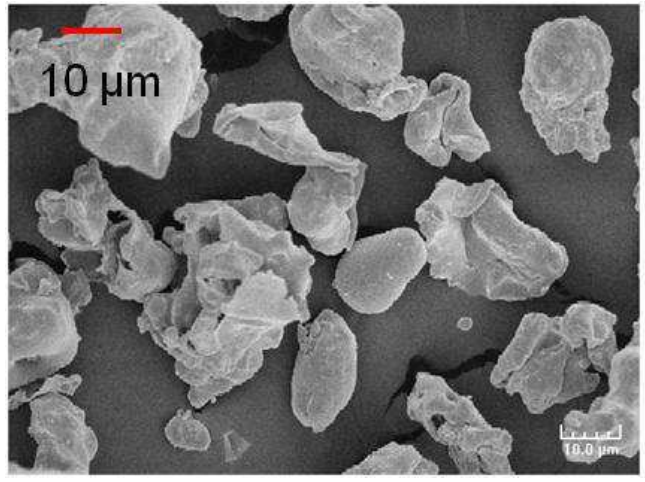

a)

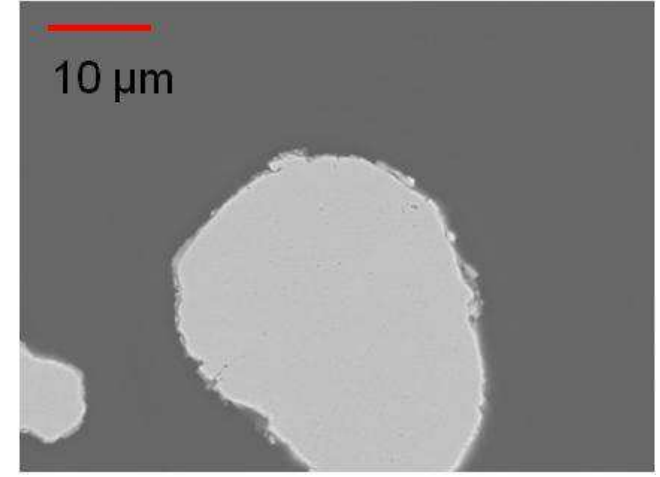

b)

Fig.3. SEM observations of 304L stainless steel powder 


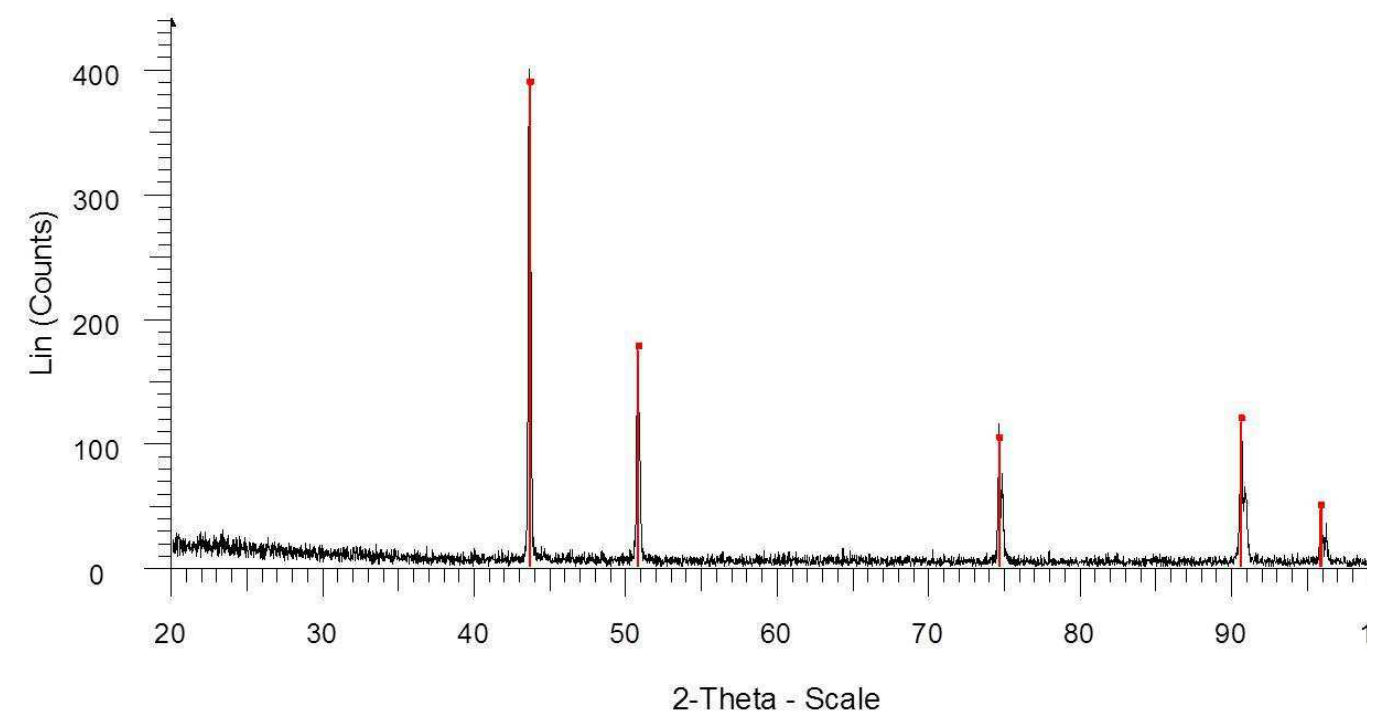

Fig.4. XRD analysis of 304L stainless steel powder

\subsection{Preparation of the model $304 \mathrm{~L}(\mathrm{p})-\mathrm{ZrO}_{2}(\mathrm{~s})$ composite}

$304 \mathrm{~L}(\mathrm{p})-\mathrm{ZrO}_{2}(\mathrm{~s})$ composite was obtained due to a powder metallurgy process. It is composed of 60 vol\% TZ-3Y-E zirconia with 40 vol\% 304L stainless steel. To reduce the porosity in the sample, organic binder was avoided during the powder preparation. The ceramic and metal powders were mixed and homogenized during $30 \mathrm{~min}$ in a planetary blender TURBULA. To prepare a homogeneous blend at the particles scale, a milling step was added to the process. The mixed powder was milled during $5 \mathrm{~min}$ at a low speed in an annular carbide ring mill.

After the powder preparation, a two steps compressive process was used to optimize the flowability of the powder in order to improve the feeding of the matrix press.

\subsubsection{Granulate step}

The granulate powder was prepared by light compaction of blended powder at an optimal value of 250 MPa. Samples ( $8 \mathrm{~mm}$ diameter discs) were compacted with an INSTRON press. These compacts were manually gently broken and sieved to produce $1 \mathrm{~mm}$ agglomerates. The resulting granules were mixed and rounded in a TURBULA for 10 min just before the compression step. 


\subsubsection{Compression step}

During a second step, granules were compacted at a pressure higher than for the granulation step with the same INSTRON press. Cylindrical pellets ( $8 \mathrm{~mm}$ diameter, $6 \mathrm{~mm}$ length) are prepared. Magnesium stearate was used as an external die lubricant.

\subsubsection{Sintering step}

Differential Thermal Analysis (Setaram TG DTA 92-16/18) measurement on stainless steel powder indicated a melting temperature of $1451{ }^{\circ} \mathrm{C}$ whereas the melting temperature of the $\mathrm{ZrO}_{2}$ powder is around $2000{ }^{\circ} \mathrm{C}$. The supplier's recommendations for the sintering temperatures are respectively 1250 ${ }^{\circ} \mathrm{C}$ for the metal powder and $1350{ }^{\circ} \mathrm{C}$ for the oxide powder.

The densifications of the metal and the ceramic powders were individually studied with a SETARAM TMA 92 dilatometer at $1400{ }^{\circ} \mathrm{C}$ under Ar- $10 \% \mathrm{H}_{2}$ atmosphere. This gaseous mixture was chosen to guaranty a reducing environment and to avoid oxidation of the metal phase.

\subsection{Characterization of the composites after sintering and after oxidation}

The microstructure of the sintered $304 \mathrm{~L}(\mathrm{p})-\mathrm{ZrO}_{2}(\mathrm{~s})$ composite samples were examined with a JEOL 6400 model Scanning Electron Microscope (SEM). Samples were coated with a hot mounting conductive resin with carbon fillers. They were abraded with 100 grains $/ \mathrm{cm}^{2}$ to $1200 \mathrm{grains} / \mathrm{cm}^{2} \mathrm{SiC}$ paper using water and $9 \mu \mathrm{m}$ to $1 \mu \mathrm{m}$ diamond polishing solution. The samples are finally cleaned with water. Before observations, a $3 \mathrm{~nm}$ gold layer was sputtered on the sample with a BALZERS SCD 050 coater.

The internal microstructure was observed with a Transmission Electron Microscope (MET Philips CM 2000). The specimens were small discs with a thickness less than $1 \mathrm{~mm}$. A dimpling procedure was used to thinning the disc in the central region while leaving a thick supporting rim to protect the sample from damage. After dimpling, the samples were ion beam polished to generate a large electron transparent area due to a Gatan Model Precision Ion Polishing System (PIPS) instrument. The voltage of the ion beam was kept at $5.0 \mathrm{kV}$ until sample perforation. Once the perforation was detected, the voltage of the ion beam was reduced to $2.5 \mathrm{kV}$ and maintained during $20 \mathrm{~min}$. Then, the voltage was lowered to $1.5 \mathrm{kV}$ again and kept to this value during $20 \mathrm{~min}$. 
X-ray diffraction (XRD) with a D 5000 Siemens diffractometer at ambient temperature and with a D8 advance Bruker diffractometer + HTK Anton-Paar chamber at high temperature was used to characterize the initial and oxidized samples.

Auger analysis AES was carried out on a radial cross section sample surface with a spectrometer RiberCameca ultra vacuum chamber equipped with a non monochromatic X-ray beam and associated with a Mac3 analyzer. Such an equipment provides high spatial resolution $(\sim 200 \mathrm{~nm}$ corresponding to the beam size). It offers the possibility to detect elements at low concentrations $(0.5-1 \%$ of the atomic composition of the sample).

\subsection{Corrosion of 304 $\mathrm{L}(\mathrm{p})-\mathrm{ZrO}_{2}(\mathrm{~s})$ composite - Thermogravimetric analysis (TGA)}

The M(p)-CMC(s) samples used for TGA analysis were $1 \mathrm{~mm}$ thin disks cut in the center of the sintered pellets. This design allows considering that the mass change is mainly due to the contribution of the two based faces of the disc. Oxidation experiments are performed in a symmetric thermogravimetric analyzer (SETARAM TGA16 with Pt-Rh $6 \%$ Pt-Rh $30 \%$ thermocouple). Open alumina crucible was used to maintain the sample in the isothermal area of the furnace. The temperature was raised up to $700{ }^{\circ} \mathrm{C}$ or $800{ }^{\circ} \mathrm{C}\left(30{ }^{\circ} \mathrm{C} / \mathrm{min}\right)$ under free flowing helium atmosphere at atmospheric pressure $(2 \mathrm{~L} / \mathrm{h})$. The oxygen impurity in helium was analyzed at the furnace outlet with an oxygen probe (Systech Instruments 900, accuracy: $1 \mathrm{ppm}$ at $20^{\circ} \mathrm{C}$ ).

After $7 \mathrm{~min}$ at $700{ }^{\circ} \mathrm{C}$ or $800{ }^{\circ} \mathrm{C}$, helium was switched to a mixture of $20 \%$ oxygen in helium $(2 \mathrm{~L} / \mathrm{h})$ for six hours. At the end of the plateau, the temperature was decreased as fast as possible (approximatively $10{ }^{\circ} \mathrm{C} / \mathrm{min}$ ) to avoid microstructure change during the cool down.

Irreversible transformations such as cracks can occur during the oxidation of the composite. These events are emissive and cause acoustic waves. Some of the thermogravimetric tests were done with an in situ coupling device (figure 5) to follow the emitted acoustic waves. Specific care should be brought to the device in order to not disturb the thermogravimetric analysis [12]. 


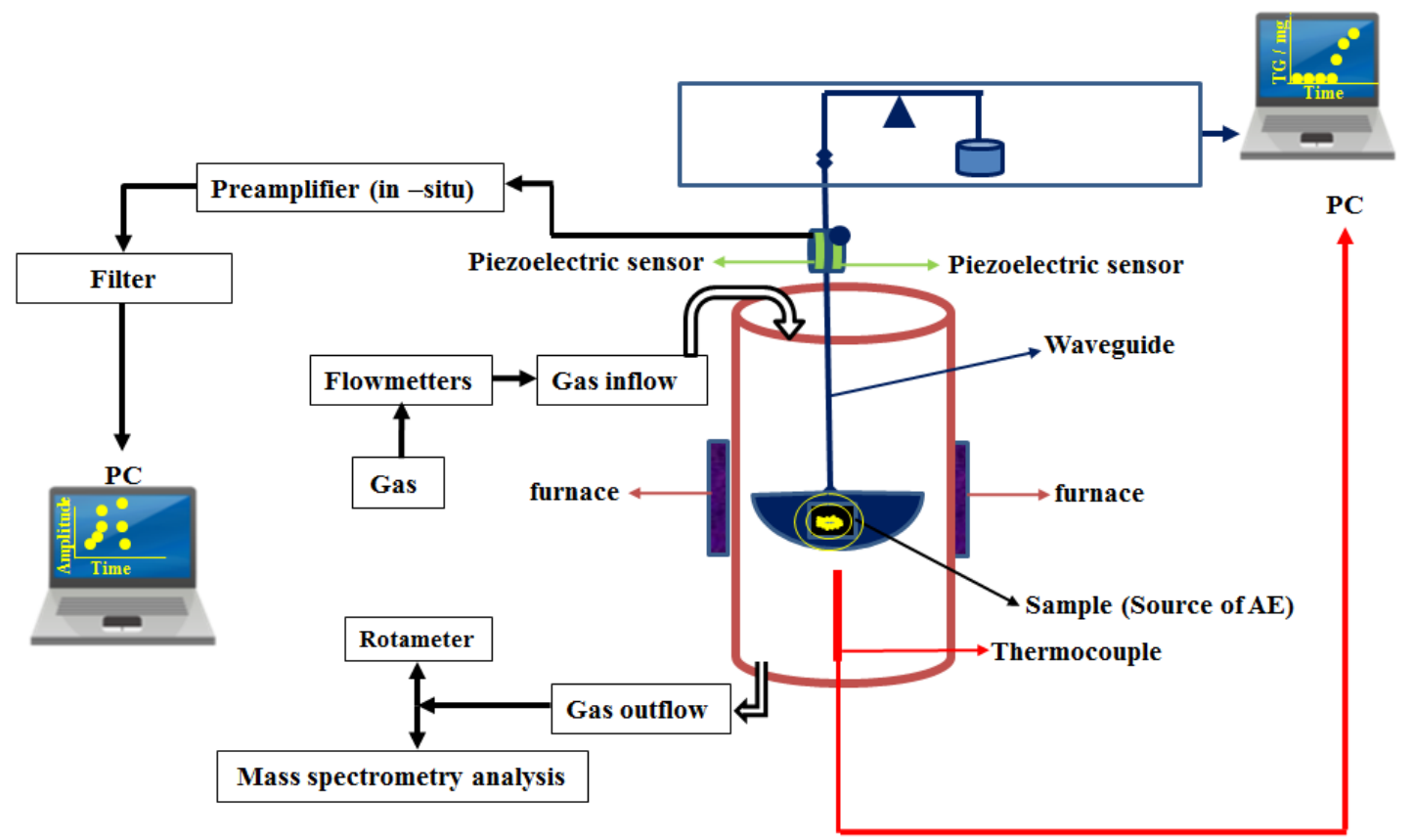

Fig.5. Acoustic emission associated to TGA measurement

The sample was deposited on an alumina waveguide in order to transmit acoustic signals from the sample to the acoustic emission transducers. The sensors (Pico type, $4 \mathrm{~mm}$ diameter) were linked to an acquisition chain which amplified (acquisition threshold is about $30 \mathrm{~dB}$ ) and recorded all acoustic signals. The parameters of the acquisition chain are given in Table III:

Table III. Parameters of the acoustic acquisition chain.

\begin{tabular}{ccccc}
\hline Instrumentation & $\begin{array}{c}\text { Data } \\
\text { acquisition card }\end{array}$ & $\begin{array}{c}\text { Filter of the } \\
\text { preamplifier }\end{array}$ & $\begin{array}{c}\text { Frequency } \\
(\mathbf{K H z})\end{array}$ & $\begin{array}{c}\text { Model of the } \\
\text { amplifier }\end{array}$ \\
\hline Characteristic & PIC 2 & $10-1200$ & 300 & $2 / 4 / 6$ gain : \\
& 2 chains & $\mathrm{KHz}$ & $40 \mathrm{~dB}_{\mathrm{AE}}$ \\
\hline
\end{tabular}

\section{Results and Discussion}

\subsection{Preparation of $304 \mathrm{~L}(\mathrm{p})-\mathrm{ZrO}_{2}(\mathrm{~s})$ composite}

\subsubsection{Compaction}


Several pressures from 250 to $500 \mathrm{MPa}$ were tested for the compression step in order to obtain the best initial green density and samples free of cracks (end capping could easily occurs during the ejection of the pellet as there was not counter pressure available on our press [13]). The optimal green density value was obtained with a pressure of $400 \mathrm{MPa}$. The geometrical density of the pellet is equal to $65 \%$ of the theoretical density after the second step compaction pressure at $400 \mathrm{MPa}$.

\subsubsection{Sintering of $304 \mathrm{~L}(\mathrm{p})-\mathrm{ZrO}_{2}(\mathrm{~s})$ composite}

The stainless steel and $\mathrm{ZrO}_{2}$ shrinkage curves at $1400{ }^{\circ} \mathrm{C}$ are shown in figure 6-a and 6-b respectively. During the temperature rise, $\mathrm{ZrO}_{2}$ exhibits a fast and important shrinkage compared to stainless steel which principally presents a thermal expansion up to 2 hours after the beginning of the thermal treatment. The metal particles embedded in the zirconia matrix which percolates are not responsible for the sintering. The $\mathrm{ZrO}_{2}$ particles sinter around the metal ones.

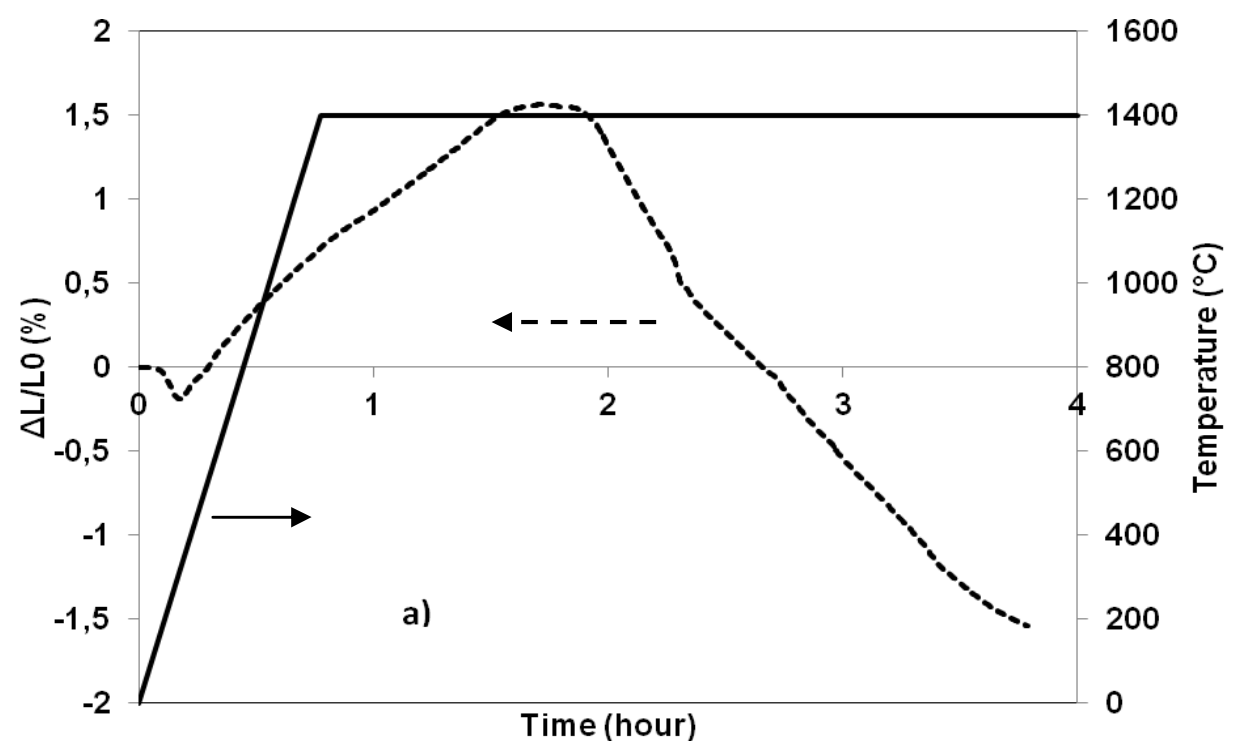




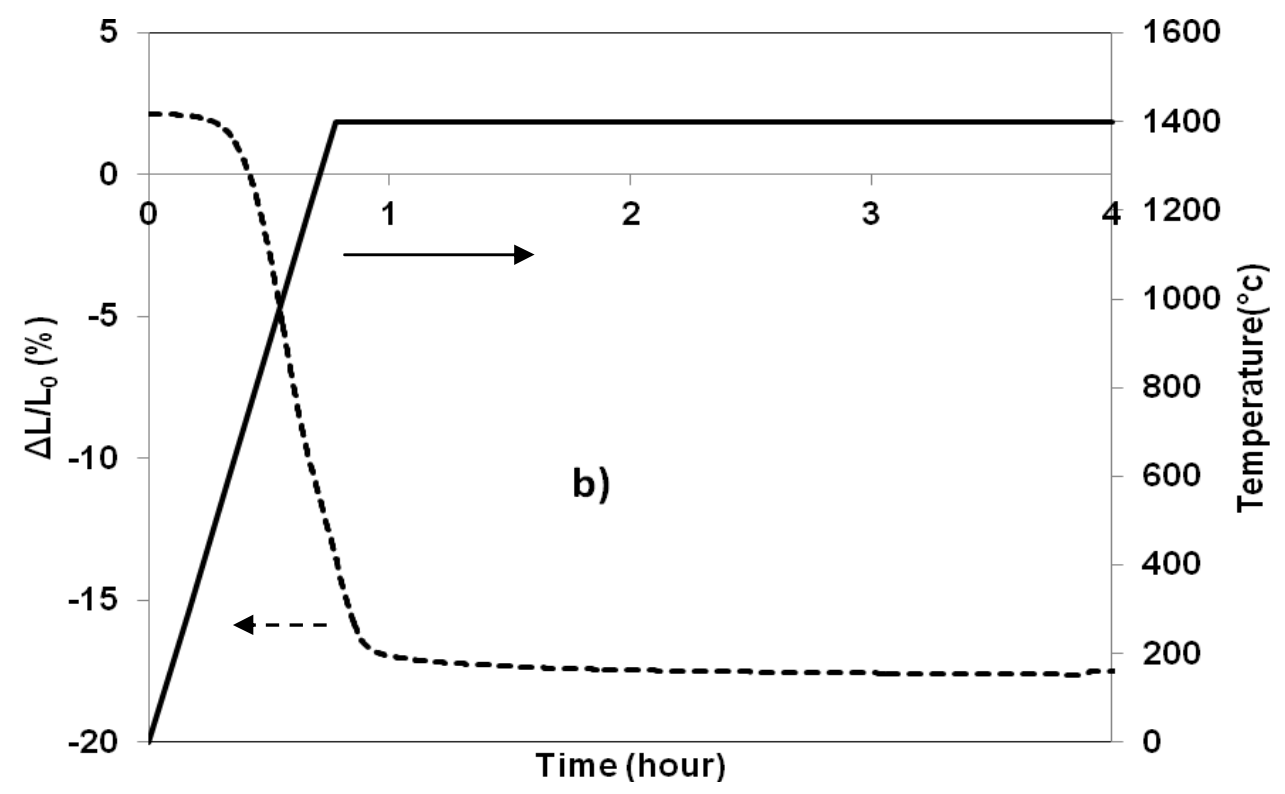

Fig.6. Shrinkage curves at $1400{ }^{\circ} \mathrm{C}$, a) $304 \mathrm{~L}$, b) $\mathrm{ZrO}_{2}$.

A dilatometric curve of a composite pellet is presented in figure 7. During the temperature rise, the density of the sample increased to more than $95 \%$ of the theoretical density. The maximum of the densification rate occurs around $1250{ }^{\circ} \mathrm{C}, 2$ hours after the beginning of the thermal treatment, in good agreement with the zirconia shrinkage. Then, the rate of densification decreased to a stable value during the plateau. The final geometrical density reaches $96 \%$ of the theoretical density. 


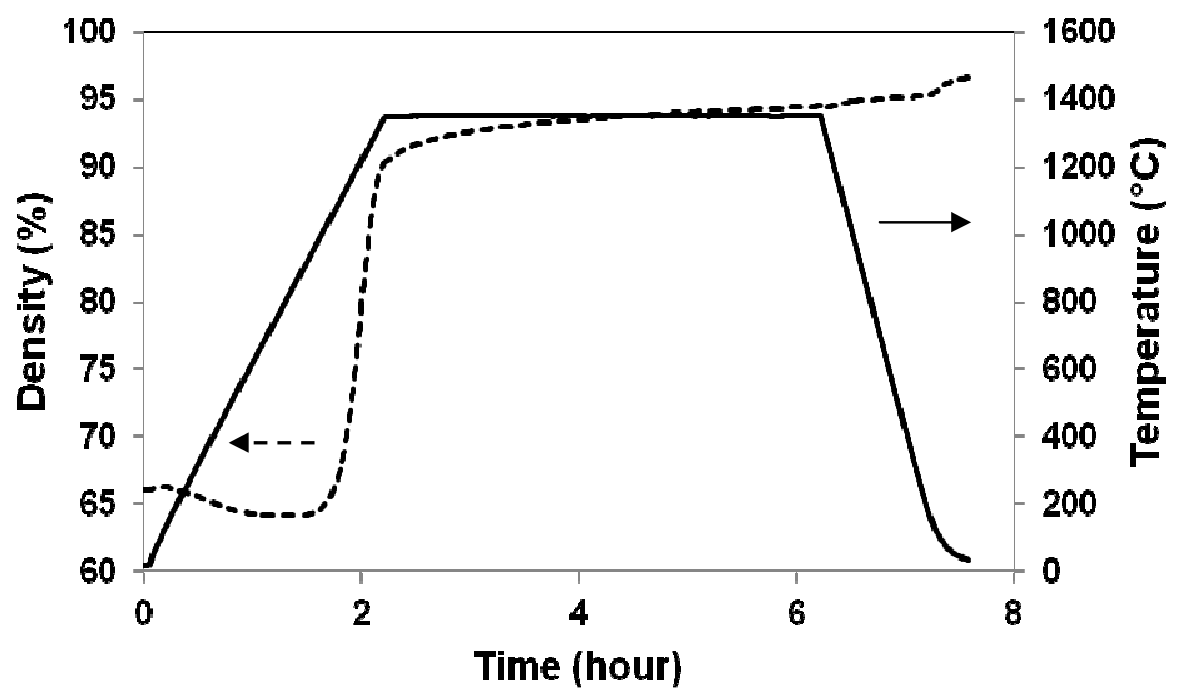

Fig.7. Dilatometric curve of $304 \mathrm{~L}$ (p)- $\mathrm{ZrO}_{2}$ (s) composite versus time of thermal treatment.

The sintering temperature of the composite was then fixed to $1350{ }^{\circ} \mathrm{C}$ which is $100{ }^{\circ} \mathrm{C}$ below the stainless steel melting point. This prevents from a liquid phase formation and any exudation phenomenon. The pellets were thus sintered at $1350{ }^{\circ} \mathrm{C}$ for 4 hours under $\mathrm{Ar}-10 \% \mathrm{H}_{2}$ atmosphere.

To optimize the sintered density of the $304 \mathrm{~L}(\mathrm{p})-\mathrm{ZrO}_{2}(\mathrm{p})$ composite samples, a parametric study has been done considering the second step compaction pressure. Figure 8 shows the influence of the compaction pressure on the density of the composite samples sintered at $1350{ }^{\circ} \mathrm{C}$. An optimal pressure was found at $400 \mathrm{MPa}$ leading to $97 \%$ of the theoretical density which ensures a closure of the porosity. 


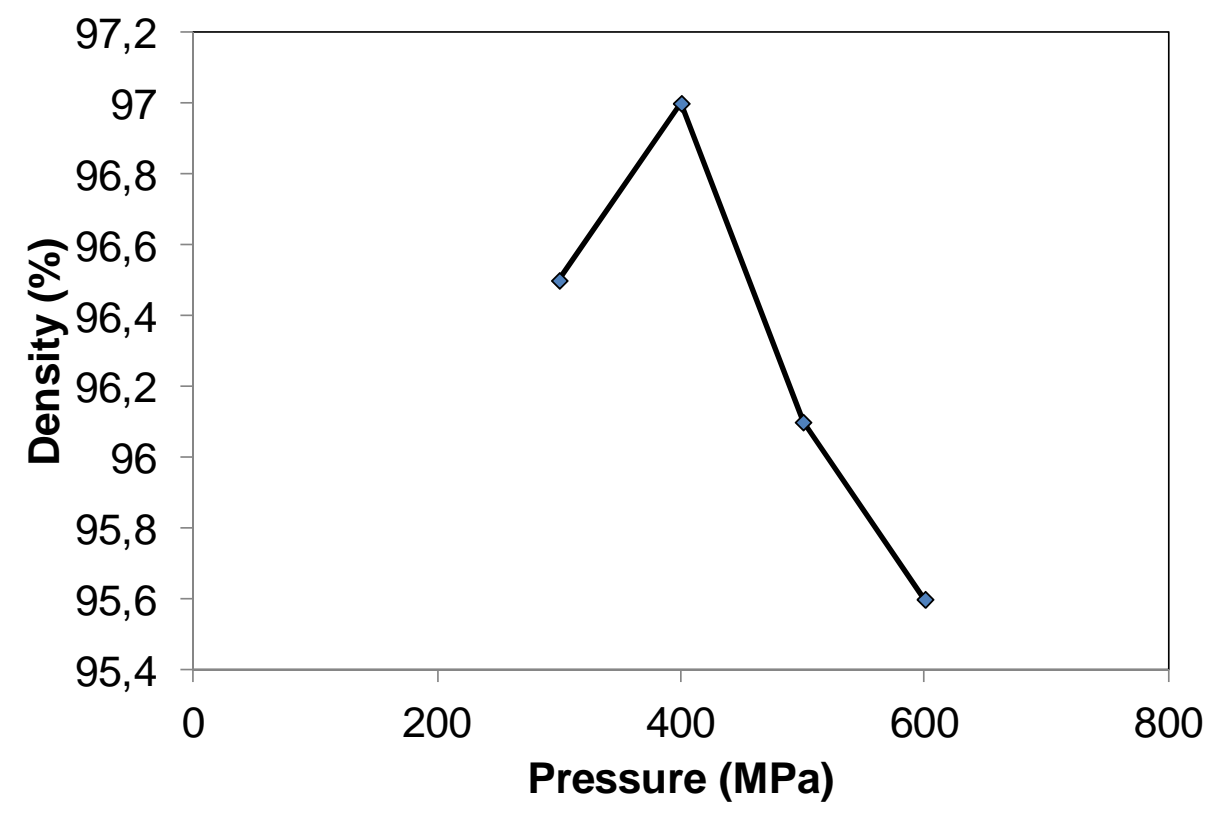

Fig.8. Density of $304 \mathrm{~L}(\mathrm{p})-\mathrm{ZrO}_{2}(\mathrm{p})$ composite after sintering at $1350{ }^{\circ} \mathrm{C}$ versus second step compaction pressure.

\subsection{Characterization of the sintered $304 \mathrm{~L}(\mathrm{p})-\mathrm{ZrO}_{2}(\mathrm{~s})$ composite}

SEM observation of $304 \mathrm{~L}(\mathrm{p})-\mathrm{ZrO}_{2}(\mathrm{p})$ sintered composite is presented in figure 9 . The final density of this sample, measured with a pycnometry method, is $97.6 \pm 0.4 \%$ of the theoretical density. The figure shows uniformly dispersed metal particles in the $\mathrm{ZrO}_{2}$ matrix. The size of the metal particles is coherent with the initial stainless steel particle size. This dense sample was free of internal cracks and only small pores can be distinguished. 


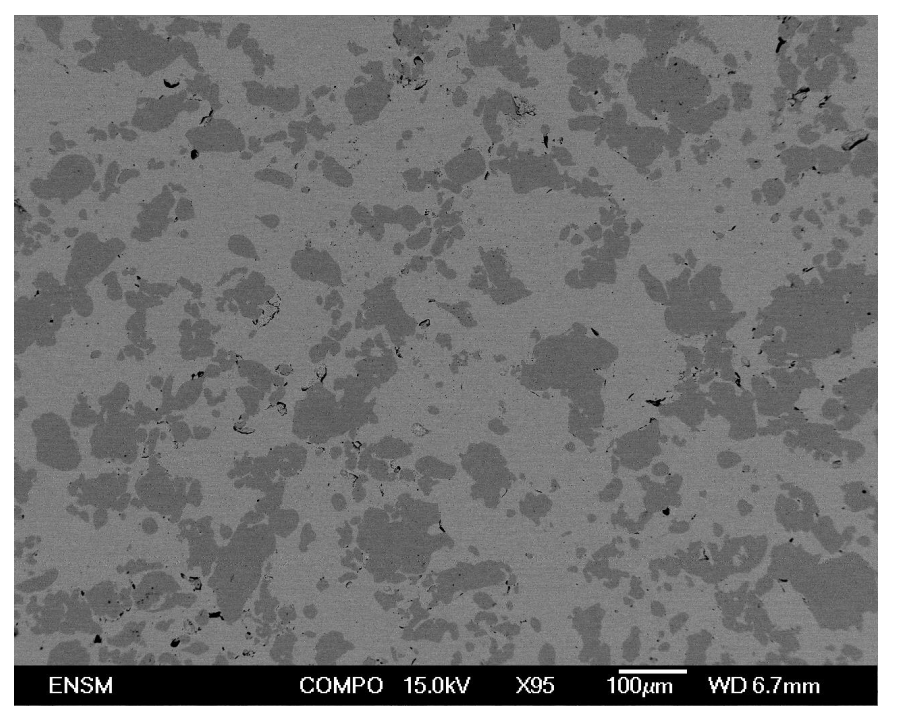

Fig.9. SEM observation of $304 \mathrm{~L}(\mathrm{p})-\mathrm{ZrO}_{2}$ (s) sintered composite (dark grey : metal particles dispersed in $\mathrm{ZrO}_{2}$ matrix; back dots : pores)

At the nanoscale level, TEM observations exhibited a well defined metal/zirconia interface (figure10). It is interesting to notice that the native $\mathrm{Cr}_{2} \mathrm{O}_{3}$ scale is not present at this interface. It indicates that the pre-existing chromia layer may has been dissolved in zirconia during the sintering [14]. However, the corresponding solid solution is not observed by TEM at the vicinity of the $\mathrm{ZrO}_{2} / 304 \mathrm{~L}$ interface, probably due to a long range diffusion of $\mathrm{Cr}$ in $\mathrm{ZrO}_{2}$ and/or a low concentration.

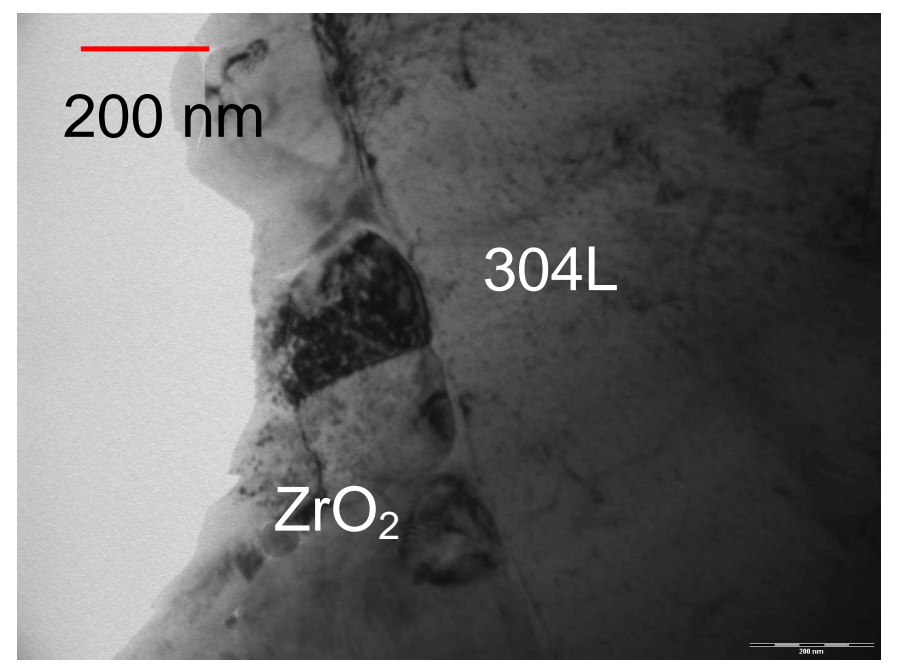

Fig.10. TEM observations of sintered $304 \mathrm{~L}(\mathrm{p})-\mathrm{ZrO}_{2}(\mathrm{~s})$ composite 
The XRD diagram (figure11) of the sintered $304 \mathrm{~L}(\mathrm{p})-\mathrm{ZrO}_{2}(\mathrm{p})$ composite presents mainly peaks of the austenitic stainless steel phase and of the high temperature tetragonal $\mathrm{ZrO}_{2}$ phase (with small amount of monoclinic $\mathrm{ZrO}_{2}$ ); those peaks are not well centered to the reference peaks. This shift can be attributed to under stoechiometric zirconia. The presence of an iron phase is due to the decomposition of the alloy during the cooling at the end of the sintering cycle, the cooling speed being too low to freeze the high temperature structure. In fact we could observe using in situ XRD that iron dissolves in the alloy if samples are sumitted again to temperature as high as $800{ }^{\circ} \mathrm{C}$. Finally, stainless steel is the only metallic phase to be taken into account during the oxidation treatment.

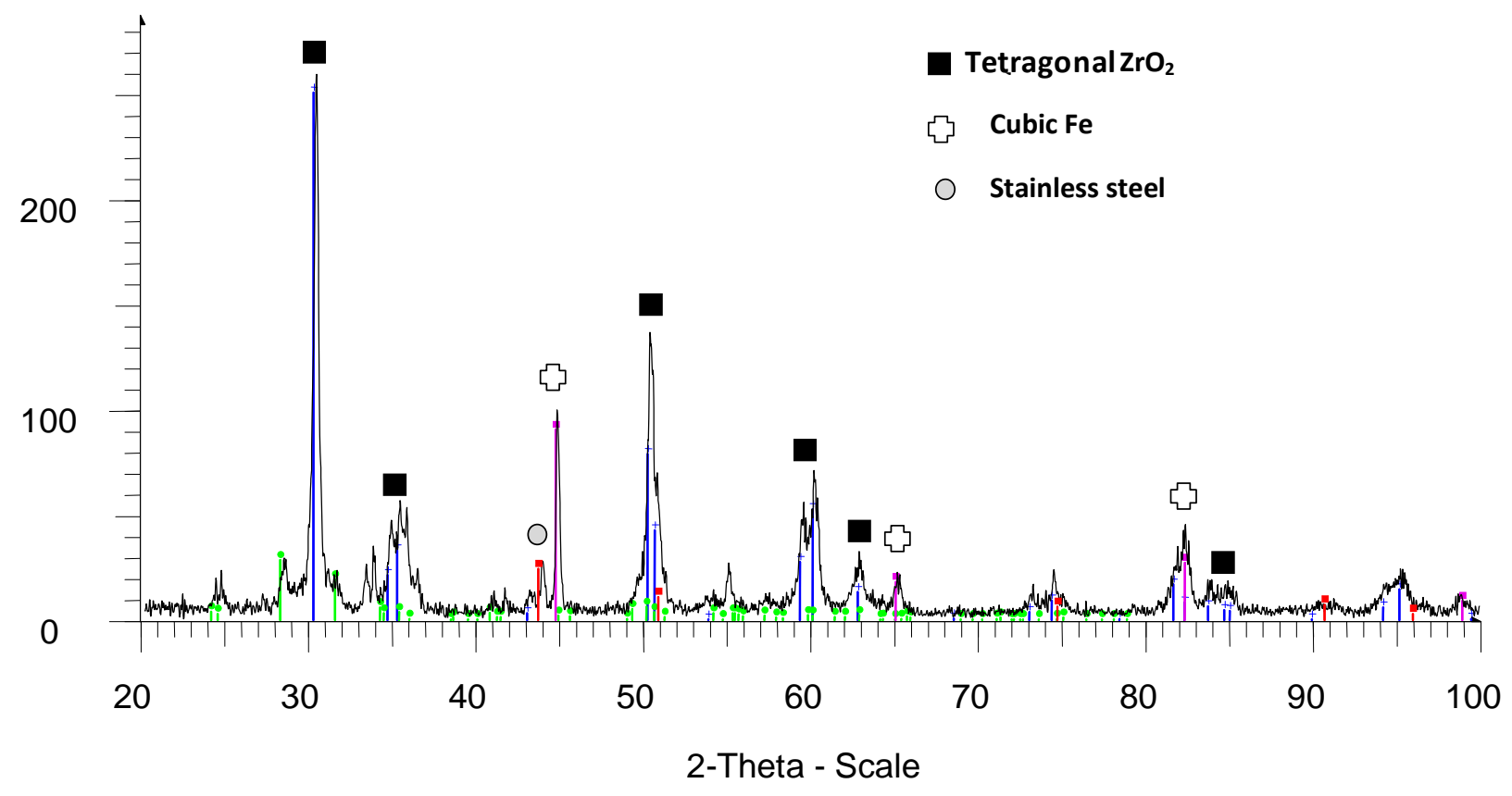

Fig.11. XRD diagram of sintered $304 \mathrm{~L}(\mathrm{p})-\mathrm{ZrO}_{2}(\mathrm{~s})$ composite.

\subsection{Oxidation of the $304 \mathrm{~L}(\mathrm{p})-\mathrm{ZrO}_{2}(\mathrm{~s})$ composite}

Figure 12 presents the kinetic curves of $304 \mathrm{~L}(\mathrm{p})-\mathrm{ZrO}_{2}(\mathrm{p})$ composite during the oxidation at $700{ }^{\circ} \mathrm{C}$ and $800{ }^{\circ} \mathrm{C}$. Fractional conversion $(\alpha)$ represents the ratio between the experimental mass obtained from TGA and the theoretical mass gain necessary to totally oxidize the metal phase. The first section of both curves (a) corresponds to the mass gain due to the presence of $50 \mathrm{ppm}$ of oxygen in helium before introduction of oxygen at the plateau. In section (b), the rapid mass gain corresponds to the introduction 
of oxygen and thus to the increase in the oxygen partial pressure to the desired value. Finally, section (c) presents the isothermal and isobaric part of the experiment. The fast initial increase in mass gain shows that the zirconia matrix allows the diffusion of oxygen species. Diffusion of oxygen in $\mathrm{ZrO}_{2}$ is in fact very fast as expected with the high ionic conductivity of yttrium doped zirconia. The composite oxidation behavior is not the usual stainless steel parabolic ones nor in section (b) neither in section (c).

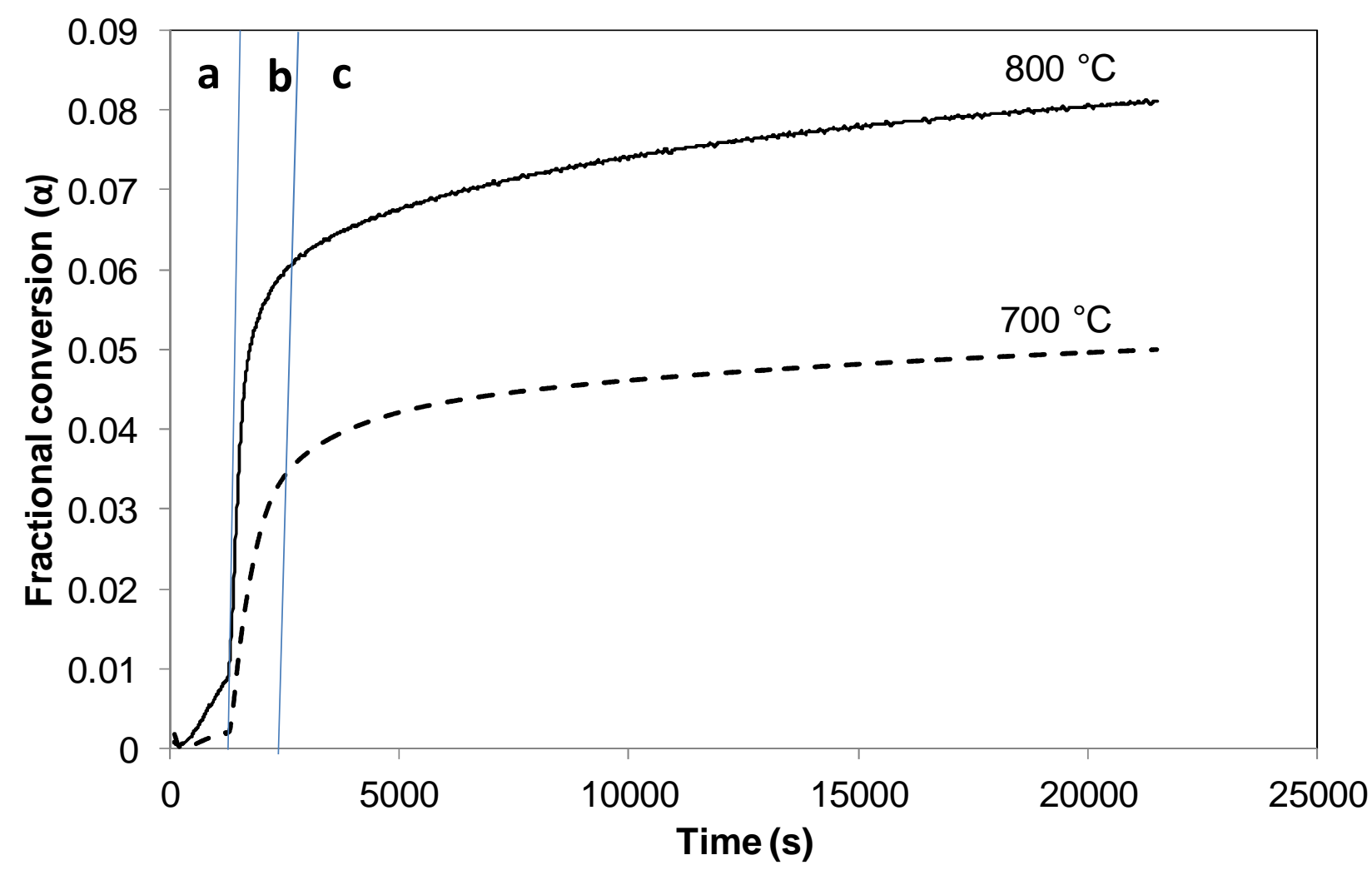

Fig.12. Fractional conversion $(\alpha)$ versus time for the oxidation of $304 \mathrm{~L}(\mathrm{p})-\mathrm{ZrO}_{2}(\mathrm{~s})$ composite at $700{ }^{\circ} \mathrm{C}$ and $800{ }^{\circ} \mathrm{C}$.

A SEM microview at low magnification of the oxidized composite oxidized at $800{ }^{\circ} \mathrm{C}$ is presented in figure 13. The surface of metallic particles directly in contact with the oxidizing atmosphere is covered with a thin oxide scale. On the other hand, in the composite core, all the metallic particles which are not directly in contact with the oxidizing atmosphere are surrounded by an oxide layer whose the thickness appears to be irregular. Many cracks in the zirconia matrix can be observed; most of them are connected to the oxidized stainless steel particles. 


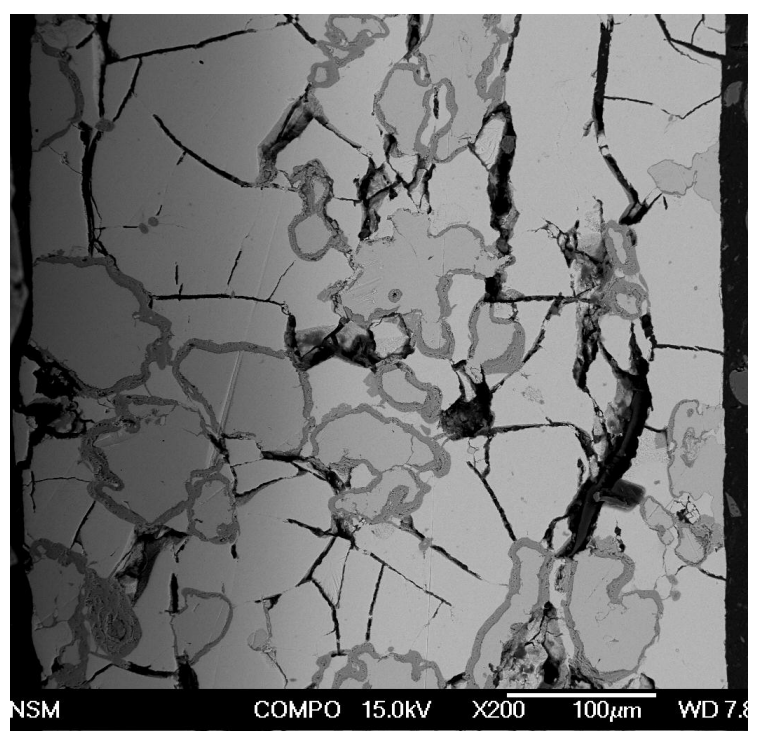

Fig.13. SEM observation of $304 \mathrm{~L}(\mathrm{p})-\mathrm{ZrO}_{2}$ (s) composite oxidized at $800{ }^{\circ} \mathrm{C}$ during 6 hours

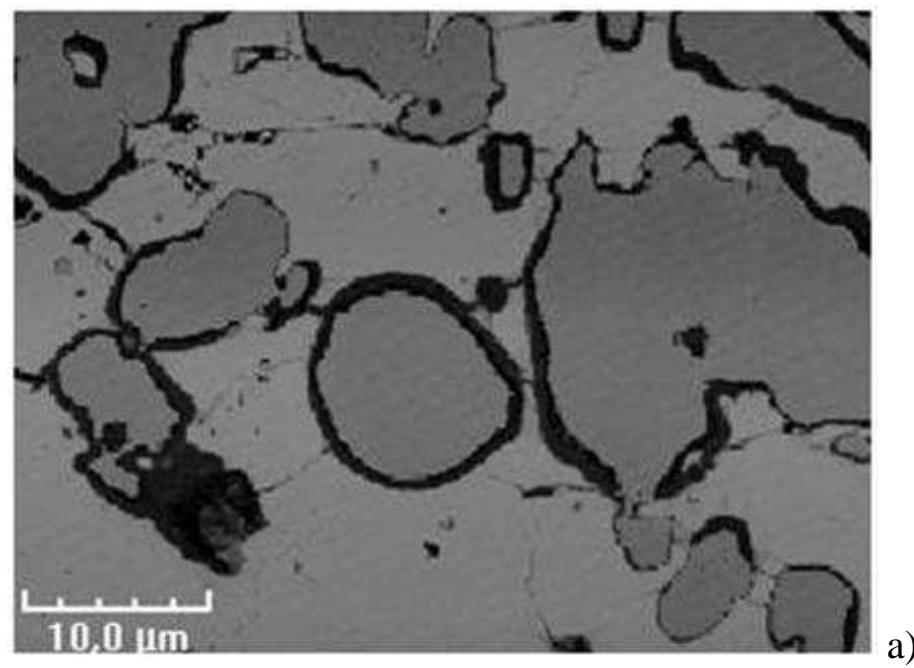

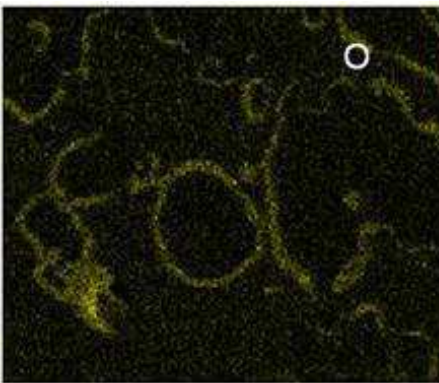

b)

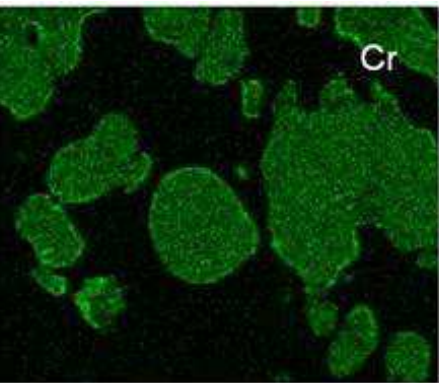

c)

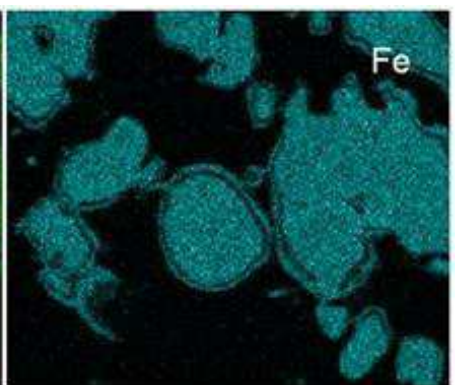

d)

Fig.14. a) SEM observation of oxidized $304 \mathrm{~L}(\mathrm{p})-\mathrm{ZrO}_{2}$ (s) composite at $800^{\circ} \mathrm{C}$, b) oxygen, c) chromium and d) iron cartographies. 
Figures 14-a shows a microview of the same composite at higher magnification than in figure 13. Figur14-b-c-d show $\mathrm{O}, \mathrm{Cr}$ and $\mathrm{Fe}$ cartographies of the oxidized particles indicating that $\mathrm{Cr}$ is present all around the metallic particles whereas Fe is visible in the outermost part of the layer oxide.

At much higher magnification, figure 15 shows a stainless steel particle embedded in zirconia matrix for a sample oxidized with a fractional conversion $\alpha$ equal to 0.04 . Small nodules of $\mathrm{Cr}_{2} \mathrm{O}_{3}$ are observed all around the internal metallic interface. Those nodules are characteristic of an internal isotropic growth due to an anionic diffusion mechanism.

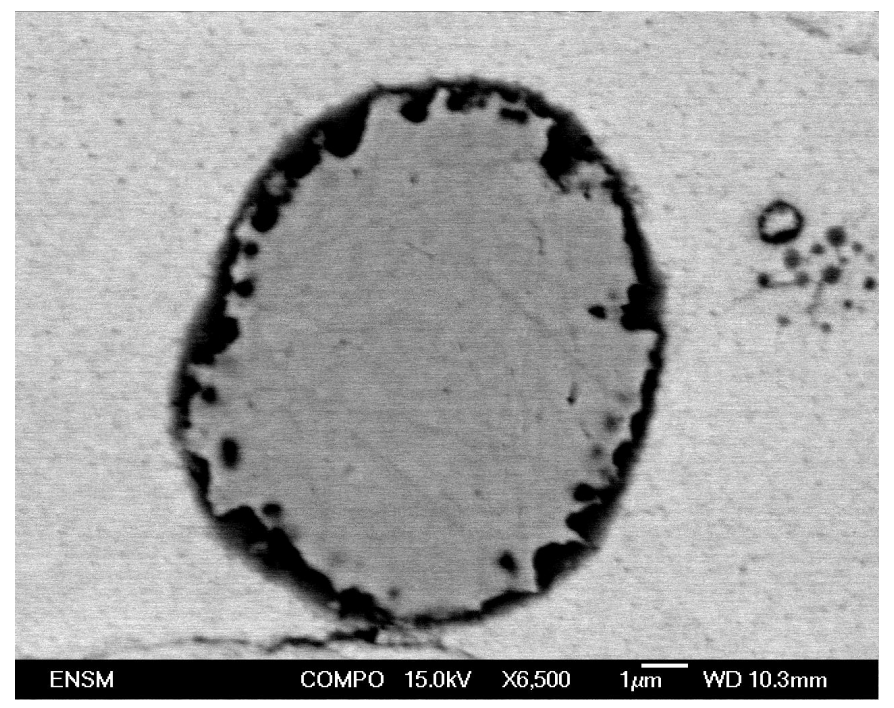

Fig.15. SEM of oxidized at $800^{\circ} \mathrm{C}$ stainless steel particles in $\mathrm{ZrO}_{2}$ for small value of fractional conversion $\alpha$ (white: $\mathrm{ZrO}_{2}$, dark: $\mathrm{Cr}_{2} \mathrm{O}_{3}$ nodules grey: $304 \mathrm{~L}$ stainless steel)

Acoustic emission (AE) was used to follow the oxidation behavior of a sample placed in the thermobalance. The mass gain was monitored by TGA simultaneously with the acoustic waves created during the oxidation. The AE signals together with the mass gain curve are shown in figure 16. It can be seen that the signal due to acoustic waves begins to increase as soon as the mass gain increases. Intense acoustic emission signals with a large number of counts occurred during all the oxidation treatment (figures 17-18) with a sharp increase in the part (b). The first initial increase in AE signal associated to the initial oxidation steps can be correlated to the oxidation process occurring at the $\mathrm{ZrO}_{2} / 304 \mathrm{~L}$ interface (nucleation and growth of $\mathrm{Cr}_{2} \mathrm{O}_{3}$ nodules). In the last part of the oxidation plateau, the increase in the AE signal was most probably due to cracks initiation and propagation in the composite. If we consider the Pilling and Bedworth ratios for $\mathrm{Fe} / \mathrm{Fe}_{2} \mathrm{O}_{3}(2.10)$ and $\mathrm{Cr} / \mathrm{Cr}_{2} \mathrm{O}_{3}(2.07)$, the 
volume expansion of the metal particles due to oxidation induces stresses in the ceramic matrix which produces cracks. Similarly, a high AE signal is observed during the cooling of the sample, due to the difference in thermal expansion coefficients between $\mathrm{ZrO}_{2}$, the oxide layer and the metal phase.
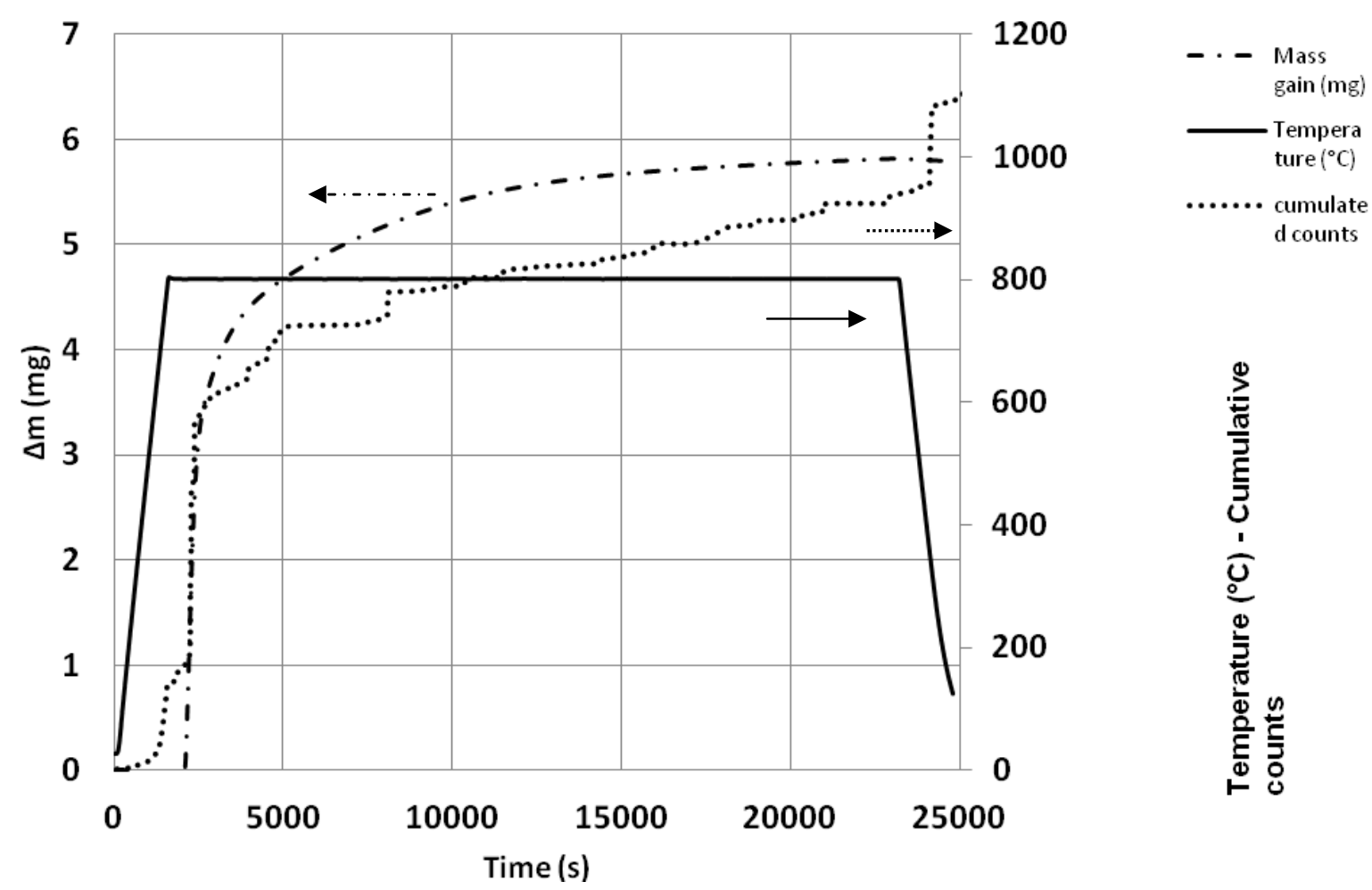

Fig 16. Thermogravimetry associated with acoustic emission of $304 \mathrm{~L}(\mathrm{p})-\mathrm{ZrO}_{2}$ (s) composite during oxidation under $20 \% \mathrm{O}_{2}$ at $800^{\circ} \mathrm{C}$.

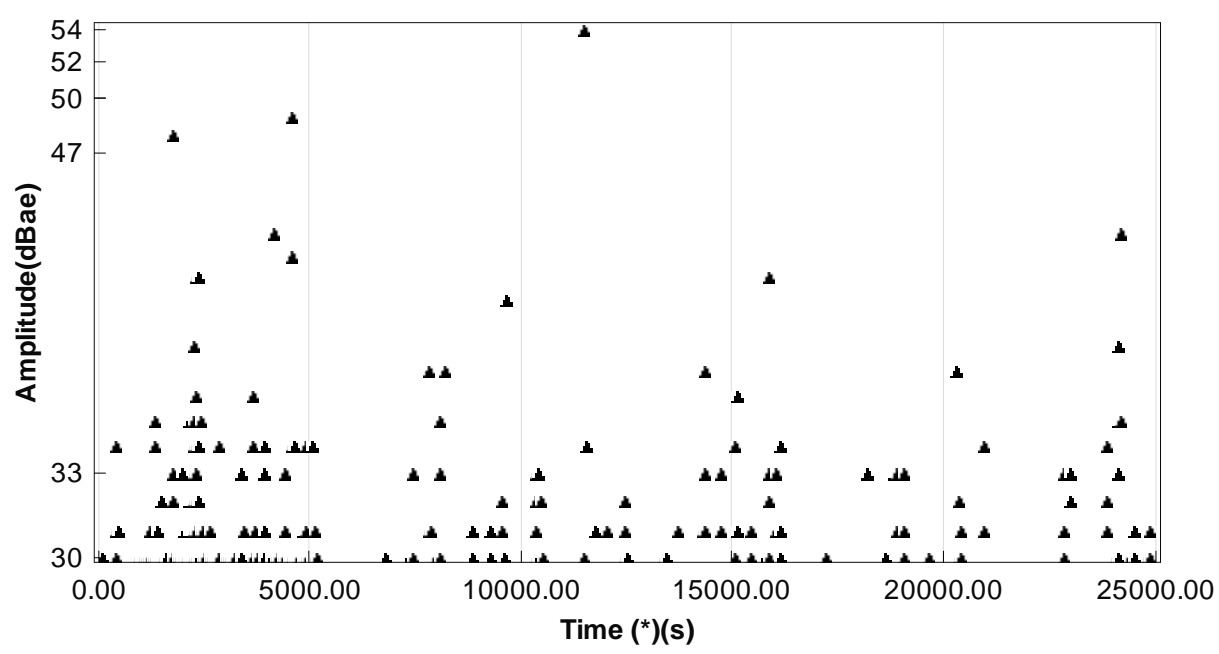

Fig 17. Acoustic emission (AE) amplitude of counts versus time. 


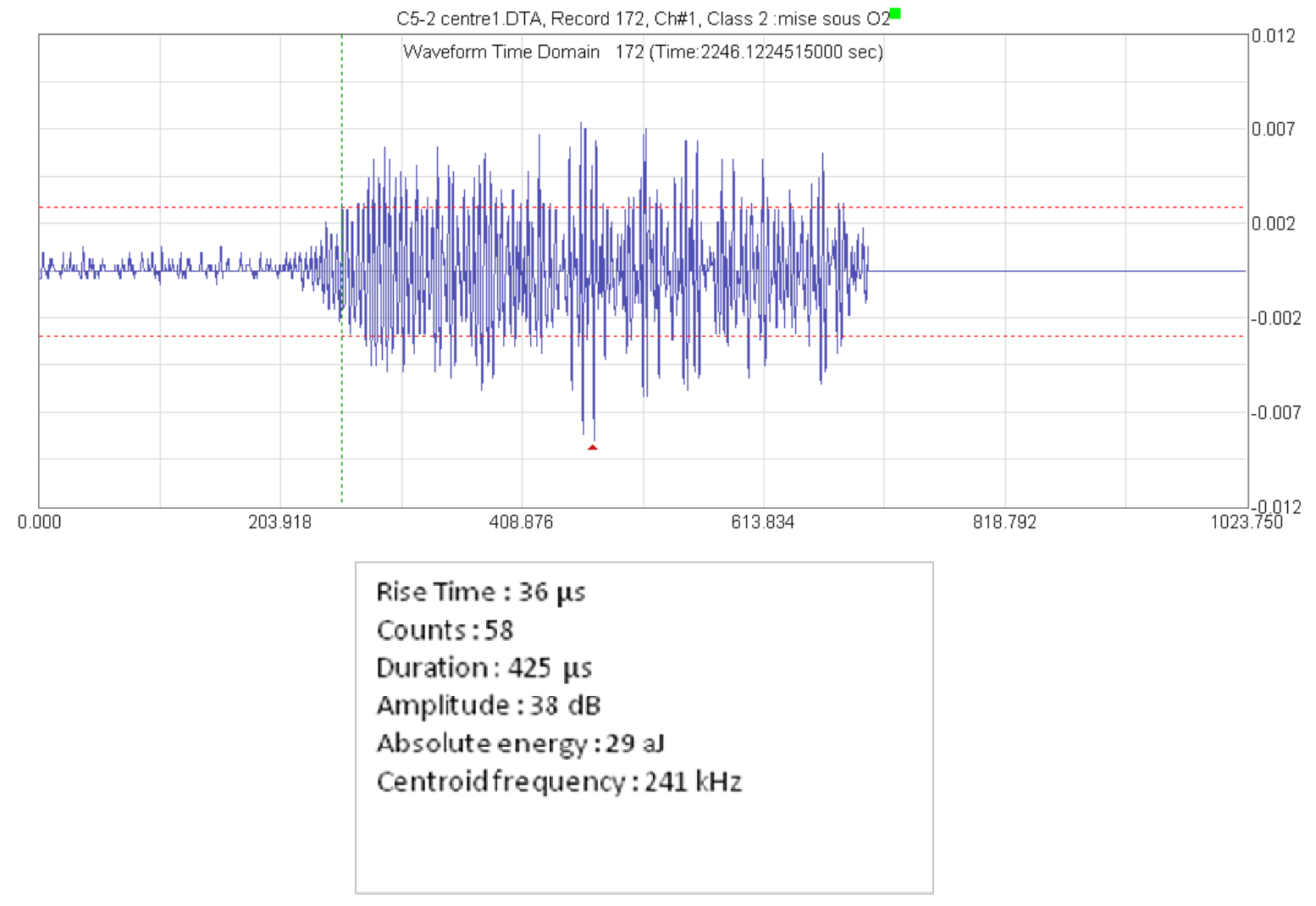

Fig 18. Parameters and wave form of a $38 \mathrm{~dB}$ count.

Auger electron spectrometry analysis (AES) (figure 19-a-b) of the $\mathrm{ZrO}_{2} / 304 \mathrm{~L}$ interface region in the oxidized composite gave additional information on the oxidation layer; figure 19-a is a microview of the interface directly obtain with the secondary electron detector connected to the Auger spectrometer. The AES profile (figure 19-b) describes the elements present along a straight line starting from the stainless steel particle, passing through the oxide layer and ending into the zirconia matrix. Iron, chromium and nickel were the major elements found in the metallic phase, as expected. At the metaloxide interface, the amount of chromium increases, whereas those of iron and nickel decrease. Deeper in the oxide layer, it can be observed a decrease in the amount of chromium and an increase in the iron amount and, at a lesser extent, in the amount of nickel. Then near the zirconia/oxide interface, the oxide layer is rich in iron. While passing the zirconia phase, metallic elements are no more detected thus no diffusion of the oxide cations in the zirconia matrix can be suspected. 


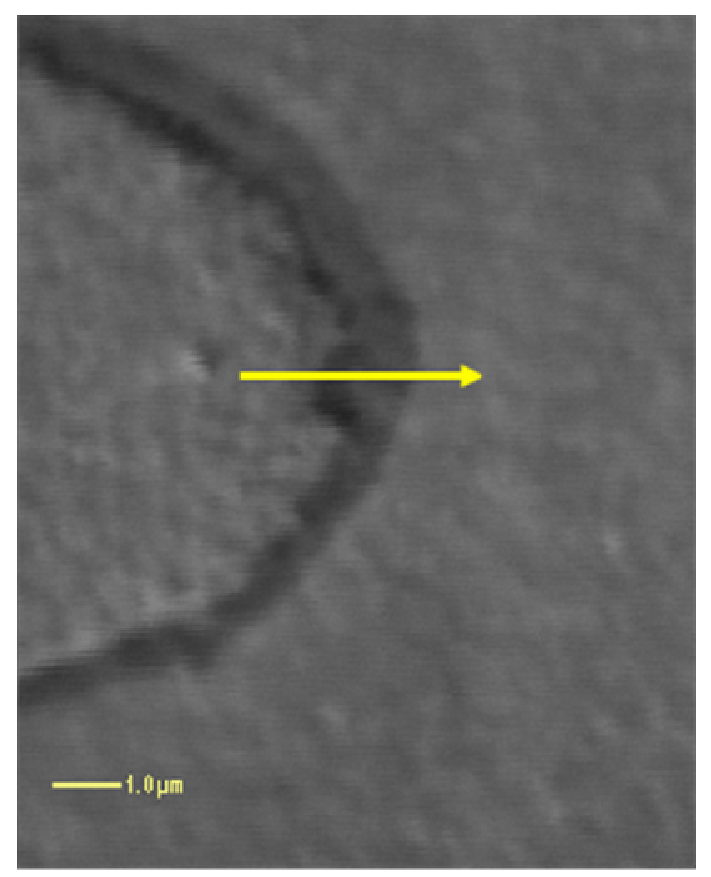

a) SEM picture

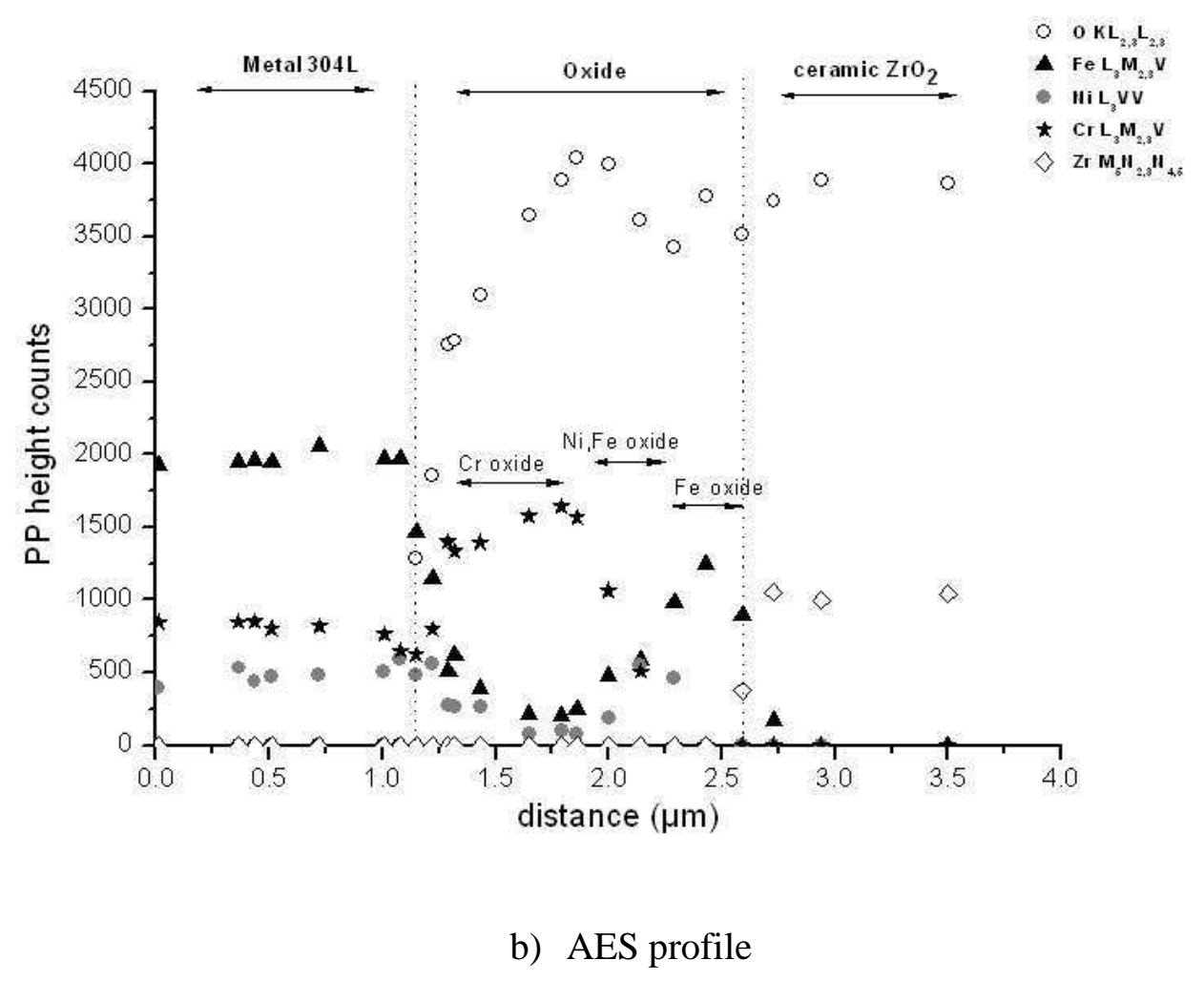

Fig.19. a) SEM pictures and b) AES profile of oxidized $304 \mathrm{~L}(\mathrm{p})-\mathrm{ZrO}_{2}(\mathrm{~s})$ composite at $800{ }^{\circ} \mathrm{C}$ 
To ascertain the composition of the oxide layer, XRD analysis (figure 20) has been performed on a composite sample oxidized at $800{ }^{\circ} \mathrm{C}$. The diffraction peaks correspond to various oxide phases: $\mathrm{Fe}_{2} \mathrm{O}_{3}$, $\left(\mathrm{Fe}_{0.6} \mathrm{Cr}_{0.4}\right)_{2} \mathrm{O}_{3}$ and tetragonal $\mathrm{ZrO}_{2}$. Tetragonal $\mathrm{ZrO}_{2}$ peaks are well centered; this shows that, as expected, $\mathrm{ZrO}_{2}$ is stoechiometric after oxidation.

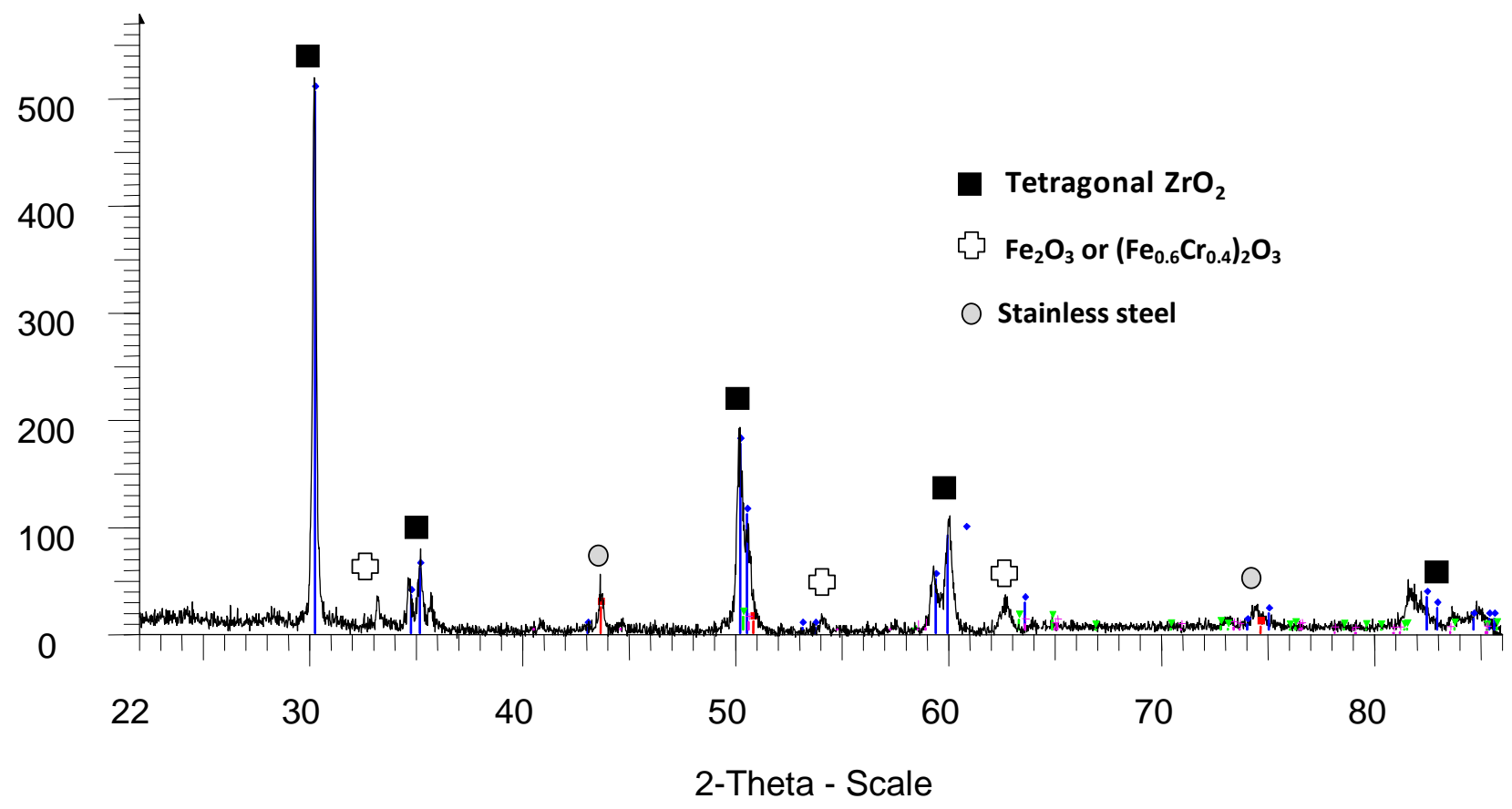

Fig.20. XRD diagram of oxidized $304 \mathrm{~L}(\mathrm{p})-\mathrm{ZrO}_{2}(\mathrm{~s})$ composite at $800{ }^{\circ} \mathrm{C}$.

This assumption was verified using thermogravimetric analysis (figure 21). A pure yttrium stabilized $\mathrm{ZrO}_{2}$ pellet, sintered as the composite in the $\mathrm{H}_{2}$ reductive atmosphere, was summit to an oxygen exposure $\left(20 \%\right.$ in helium) at $800{ }^{\circ} \mathrm{C}$. After oxidation, we observed a mass gain and the black color of the sintered pellet disappears for a white one. The sintered $\mathrm{ZrO}_{2}$ passes from the under stoechiometric state to the stoechiometric one. Base on the TGA result and on equation E1, we can calculate the value of the non-stoechiometry $\mathrm{x}: \mathrm{x}=0.03$.

$$
\mathrm{Y}_{0.03} \mathrm{Zr}_{0.97} \mathrm{O}_{2-\mathrm{x}}+\mathrm{xO}_{2}=\mathrm{Y}_{0.03} \mathrm{Zr}_{0.97} \mathrm{O}_{2}
$$




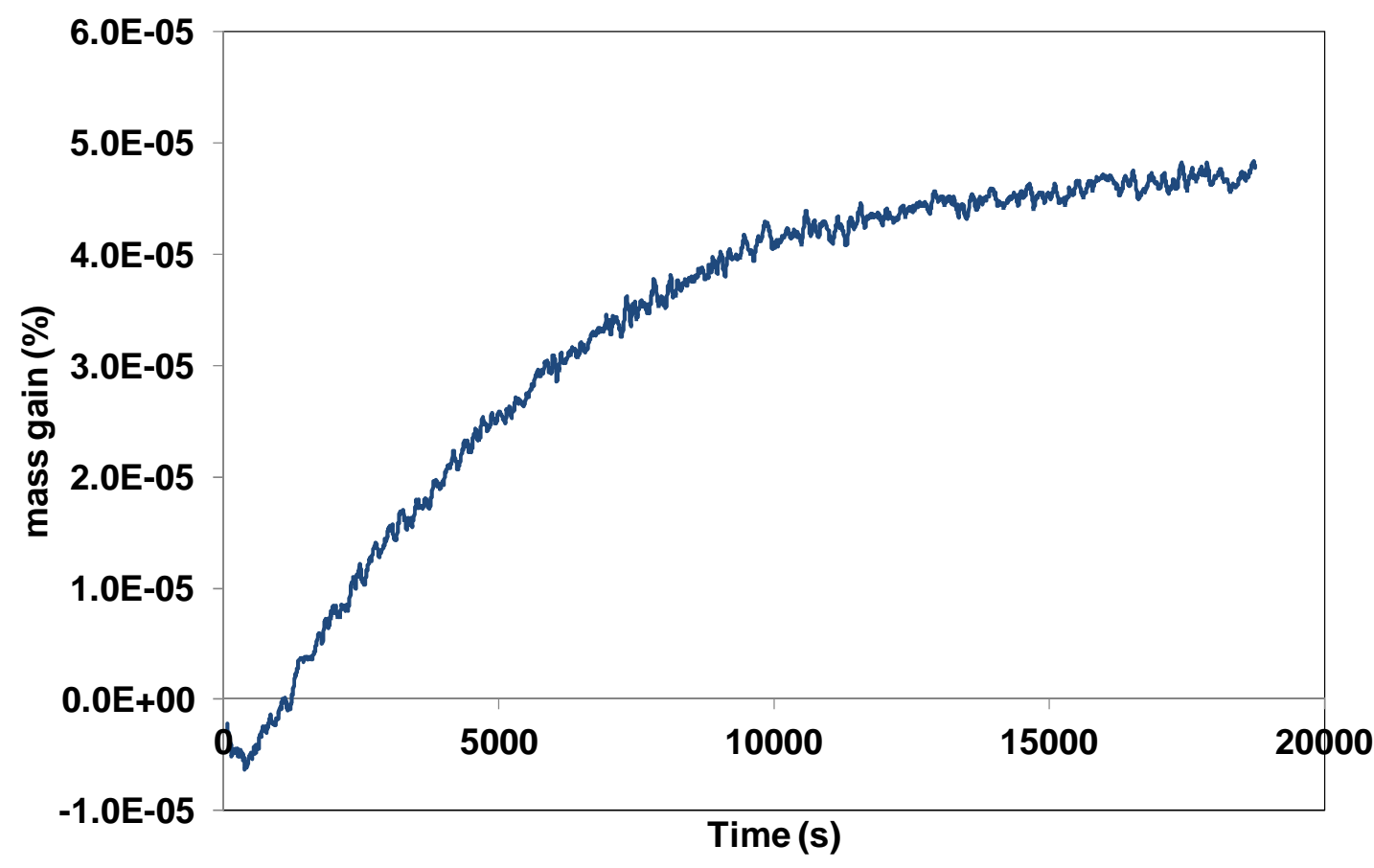

Fig.21. Thermogravimetric analysis of TZ-3Y-E $\mathrm{ZrO}_{2}$ sintered pellet during an oxidation at $800{ }^{\circ} \mathrm{C}$.

\section{Discussion}

From TGA, SEM, AES and XRD characterization of the oxidized 304L(p)- $\mathrm{ZrO}_{2}(\mathrm{~s})$ composite, an oxidation scenario can be proposed. During the initial oxidation period (section (b) in figure 12: high kinetic rate), at the sample surface, a protective chromia scale appears on the metal particles. In the core of the composite, nodules of $\mathrm{Cr}_{2} \mathrm{O}_{3}$ start to nucleate and grow around the stainless steel particles to form an inward layer. Such a non protective scale is produced both because the metal particles are not covered with a thin native and protective oxide layer after the sintering process and because the oxygen diffusion through $\mathrm{ZrO}_{2}$ is fast even in the absence of cracks at the beginning of the oxidation process. Then, after the appearance of cracks due to the volume expansion of the oxide layer, a complex 
multiphase layer, mainly based on iron and chromium, develops outside the initial discontinuous layer $\left(\mathrm{Cr}_{2} \mathrm{O}_{3}\right.$ nodules $)$ all around the metal particles.

We can calculate the critical thickness $X^{*}$ of the oxide layer around the metal particle (radius $r$ ) which can induce a critical stress $\sigma^{*}$ and the fracture of the zirconia matrix using equation 2 [15] and the mechanical parameters of stabilized $\mathrm{ZrO}_{2}$ :

$$
\sigma^{*}=\frac{E}{(1-v)}\left(\frac{r}{L / 2}\right)^{3} \frac{\left(1-1 / R_{p b}\right)}{r} X *
$$

where $R_{p b}$ is the Pilling and Bedworth ratios for $\mathrm{Cr} / \mathrm{Cr}_{2} \mathrm{O}_{3}$ (2.07); zirconia Young's modulus $\mathrm{E}$ and Poisson's ratio $v$ are respectively $180 \mathrm{GPa}$ and 0.34 , zirconia fractured stress $\sigma_{\mathrm{f}}$ is $500 \mathrm{MPa}$ and $\mathrm{L}$ is the average distance between the metal particles $(50 \mu \mathrm{m})$. In the very beginning of the composite oxidation process, if the oxide layer thickness exceeds $0.05 \mu \mathrm{m}$, the stress exceeds also $\sigma_{\mathrm{f}}$ and cracks occur in the $\mathrm{ZrO}_{2}$ matrix.

The oxidation of pure 304L stainless steel plate [16] in oxygen at high temperature usually shows parabolic behavior; the oxide grows outwards with an initial external $\mathrm{Cr}_{2} \mathrm{O}_{3}$ layer followed by growth of $(\mathrm{Cr}, \mathrm{Fe})_{2} \mathrm{O}_{3}$ layers with variable $\mathrm{Cr}$ and $\mathrm{Fe}$ proportions. The oxidation of the $304 \mathrm{~L}(\mathrm{p})-\mathrm{ZrO}_{2}(\mathrm{~s})$ model composite begins with an internal growth of $\mathrm{Cr}_{2} \mathrm{O}_{3}$ nodules. There is an inward diffusion of oxygen anions in the $\mathrm{Cr}_{2} \mathrm{O}_{3}$ layer instead of a chromium cations outward diffusion. Due to well defined interfaces between $\mathrm{ZrO}_{2}$ and the metal particles in the sintered composite, the stabilized zirconia matrix blocks the outward growth of chromium oxide until the appearance of cracks. This phenomenon was also reported in literature [15] for the oxidation of $\mathrm{ZrO}_{2}$ composites dispersed with $\mathrm{Ni}$ particles.

\section{Conclusion}

Such a comprehensive study has put in evidence an unusual behavior of a stainless steel alloy inserted in a dense $\mathrm{Y}_{2} \mathrm{O}_{3}$ partially stabilized $\mathrm{ZrO}_{2}$ matrix with respect to oxidation. An optimized powder metallurgy process was used to produce composites dispersed with metal particles with $97 \%$ of the theoretical density. 
The oxidation under $20 \% \mathrm{O}_{2}$ in $\mathrm{He}$ of the $304 \mathrm{~L}(\mathrm{p})-\mathrm{ZrO}_{2}(\mathrm{~s})$ composite at $700^{\circ} \mathrm{C}$ and $800^{\circ} \mathrm{C}$ exhibits a different corrosion behavior than pure 304L stainless steel, beginning with an internal growth of $\mathrm{Cr}_{2} \mathrm{O}_{3}$ nodules instead of a continuous external chromium oxide layer. The zirconia matrix plays a major role on the corrosion behavior of the composite. Some additional works are in progress to deeper study the kinetics and the mechanisms of oxidation of the model $304 \mathrm{~L}(\mathrm{p})-\mathrm{ZrO}_{2}(\mathrm{~s})$ composite. It would be interesting to test the composite resistance to oxidation by changing the stabilized $\mathrm{ZrO}_{2}$ matrix with $\mathrm{MgO}$ matrix. Lower oxygen diffusion coefficient would lead to a better corrosion resistance. Moreover oxidation behavior may change with the amount of open porosity in the composite.

\section{Acknowledgements}

The authors wish to thank Mr. Sao-Joao for his collaboration in the preparation of samples for TEM observations as well as Mr. Barnier for the AES analysis.

\section{References}

[1] Çelik E C,Avci E, Yilmaz F, Evaluation of Interface Reactions in thermal barrier ceramic Coatings, Surface Coatings Technology, Surface and Coatings Technology, 1997, 97, p 361.

[2] Zhu J, Lai Z, Yin Z, Jeon J, Lee S, Fabrication of $\mathrm{ZrO}_{2}-\mathrm{NiCr}$ functionally graded material by powder metallurgy, Materials Chemistry and Physics, 2001, 68, p 130-135.

[3] Nanko M, High-temperature oxidation of ceramic matrix composites dispersed with metallic particles, Science and Technology of Advanced Materials, 2005, 6, 129-134.

[4] Li J Q, Zeng X R, Tang J N, Xiao P, Fabrication and thermal properties of a YSZ-NiCr joint with an interlayer of YSZ-NiCr functionally graded material, Journal of the European Ceramic Society, 2003, p 23, 1847-1853.

[5] Kieback B, Neubrand A, Riedel H, Processing techniques for functionally graded materials, Materials Science and Engineering, 2003, A362,p 81-105.

[6] Lopez Esteban S, Bartolomé J F, Pecharroman C, Moya J S, Zirconia/stainless steel continuous functionally graded material, Journal of the European Ceramic Society, 2002, 22, p 2799-2804.

[7] Gillia O, Caillens B, Fabrication of a material with composition gradient for metal/ceramic assembly, Powder Technology 2011, 208, p 355-366 
[8] Wildan M, Edrees H J, Hendry A, Ceramic matrix composites of zirconia reinforced with metal particles , Materials Chemistry and Physics, 2002, 75, p 276-283.

[9] Jung Y G, Choi S C, Oh C S, and Paik U G, Residual stress and thermal properties of zirconia/metal (nickel, stainless steel 304) functionally graded materials fabricated by hot pressing, Journal of Materials Science, 1997, 32, p 3841-3850.

[10] Abenojar J, Velasco F, Bautista A, Campos M, Bas J A, Torralba J M, Atmosphere influence in sintering process of stainless steels matrix composites reinforced with hard particles, Composites Science and Technology, 2003, 63,p 69-79.

[11] Moral C, Bautista A, Velasco F, Aqueous corrosion behaviour of sintered stainless steels manufactured from mixes of gas atomized and water atomized powders, Corrosion Science, 2009, 51, $\mathrm{p}$ 1651-1657.

[12] Grosjean F, Kittel J, Ropital F, Serris E, Peres V, Couplage analyse thermogravimétrique et émission acoustique pour l'étude de la corrosion haute température, Spectra analyse, 2011, 279, p 3544.

[13] Balakrishna P, Chakraborthy K P, Narayanan P S A, Ramakrishnan P, Cracking, end-capping and other defects in pressed ceramic compacts, Interceram, 1992, 41, p 3

[14] Jerebtsov D A, Mikhailov G G, Sverdina S V, Phase diagram of the system: $\mathrm{ZrO}_{2}-\mathrm{Cr}_{2} \mathrm{O}_{3}$, Ceramics International, 2001, 27, p 247-250.

[15] Nanko M, Yoshimura M, Maruyama T, High temperature oxidation of $\mathrm{Y}_{2} \mathrm{O}_{3}$ Partially-Stabilized $\mathrm{ZrO}_{2}$ composites dispersed with Ni particles, Materials Transactions, 2003, 44, 4, p 736-742.

[16] Asteman H, Svensson JE, Johansson LG, Evidence for chromium evaporation influencing the oxidation of 304L: The effect of temperature and flow rate, Oxidation of Metals, 2002, 57, p 193-216. 